\title{
Substance Use and Mental Health Treatment Retention among Young Adults
}

\author{
Susie Adams ${ }^{1}$, Siobhan Morse*2, Sam Choi ${ }^{3}$, Cayce Watson ${ }^{4}$ and Brian E Bride ${ }^{5}$ \\ ${ }^{1}$ Vanderbilt University, USA \\ ${ }^{2}$ Foundations Recovery Network, The Addiction Services Division at Universal Health Services, USA \\ ${ }^{3}$ Alabama A \& M University, USA \\ ${ }^{4}$ Lipscomb University, USA \\ ${ }^{5}$ Georgia State University, USA
}

Submission:March 15, 2017; Published: March 30, 2017

*Corresponding author:Siobhan Morse, Foundations Recovery Network, The Addiction Services Division at Universal Health Services, 5409 Maryland Way, \#320 Brentwood, TN 37027; Tel: 615-870-8083; Email: Siobhan.morse@frnmail.com

\begin{abstract}
In Western and European cultures where marriage and parenthood are increasingly delayed to the late twenties and early thirties, a distinct developmental stage between adolescence and adulthood has been described as "emerging" or "young" adults. Development theory suggests that these "younger" adults have less social control and exercise higher levels of impulsivity and risky behavior than their older counterparts. This study examined the effect of age on treatment retention among adults with co-occurring substance use and mental health disorders enrolled in private, residential treatment. Study participants included 929 adults (198 young adults, 18-25 years, and 761 older adults, $\geq 26$ years) receiving private residential treatment in the U.S. Bivariate analyses, life tables, and Cox regression (survival analyses) were used to examine the effects of age on treatment retention.
\end{abstract}

\section{Introduction}

In Western and European cultures where marriage and parenthood are increasingly delayed to the late twenties and early thirties, a distinct developmental stage between adolescence and adulthood has been described as "emerging" or "young" adults [1]. As these individuals make the transition from adolescence to adulthood, when parental or authoritative and protective influences weaken, they begin to explore possible life directions in love, work, and worldviews and a new level of social freedom and responsibility is experienced. The period of emerging adulthood is filled with both opportunities and challenges. Explorations of love, work, and worldviews are fraught with the possibility of romantic rejection, failure to find work that is satisfying and meaningful, and disillusionment with the world's inequities and realities [1]. Developmental theory suggests that these "younger adults" have less social control and exercise higher levels of impulsivity than their older counterparts.

Thus, the years of young adulthood are defined not only by age and increased social responsibilities and pressures, but also by increased risky behavior. Young adulthood is a period that is developmentally associated with biological, psychological, social, and cognitive changes, along with increases in risk-taking, such as substance use [2]. According to White House estimates, three million young adults gained health insurance coverage as a result of the Affordable Care Act [3]. The increase of young adults' coverage, representing a return to pre-recession rates, is primarily a result of expanded dependent coverage [4]. In addition, approximately 60 million Americans have gained expanded mental health and substance use disorder benefits and/or federal parity protections [3].

These changes are particularly important because young adults between the ages of 18 and 25 have higher rates of substance use than any other age group [4]. The median age of onset for substance related disorders in the United States is 20 years of age [5]. The rate of substance use disorder among adults aged 18 to $25(22.0 \%)$ is 2.3 times higher than that among youths aged 12 to $17(9.4 \%)$ and 2.6 times higher than among adults aged 26 or older (8.3\%) SAMHSA (50). In a recent national sample of young adults aged 18-25 years of age, $59.6 \%$ reported current alcohol use, $10.8 \%$ reported heavy alcohol use, and $37.7 \%$ reported binge drinking (50). Of particular note, college age adults (18-22 years old) enrolled as full-time college 


\section{Global Journal of Addiction \& Rehabilitation Medicine}

students have higher binge drinking rates (39.0\%) than those enrolled part-time in college or not enrolled in college (33.4\%) [49]. Among adults 26 years and older the rates of heavy alcohol use and binge drinking steadily decline with increasing age [49].

Since 1980, college students have consistently displayed the highest rates of heavy drinking as compared to high school seniors and non-college students of the same age [6]. The developmental transition during the college years is often associated with the initiation and escalation of heavy drinking, which in turn can be associated with later life challenges that involve alcohol and other drugs [7]. Heavy drinking and the associated risks remain a high priority for universities since many of the consequences hamper student learning [8]. The impact of heavy drinking in this population also includes disturbances in physical and mental health, social and peer functioning, academic performance, and legal issues [8].

Current research indicates that students who drink heavily do not learn from past consequences and often overestimate the quantity of a period after [9] alcohol they can consume without experiencing adverse effects [9] High school seniors transitioning to college exhibit similar alcohol and substance use trends. The 2013 Monitoring the Future study found that $68.2 \%$ of high school seniors in a nationwide sample had consumed alcohol and $50.4 \%$ had used illicit drugs within their lifetime [10]. Results also revealed attitudinal shifts in students' perceptions of regular marijuana use, with $60 \%$ of 12 th grade students viewing regular use as not harmful. Over the last decade, the number of young adults who view marijuana as harmful has diminished greatly, while rates of marijuana use have increased. The increased use of marijuana combined with the perception of less harm among young adults preparing to leave for college could be indicative of future increases in use among this population [11].

Among young adults living outside their parent's home over the past 20 years there is a higher likelihood of marijuana and alcohol use [12] and college students living on campus are five times more likely to initiate marijuana use than students who live off campus [13]. The number of college students using any illicit drug has risen incrementally since 2006 , with the increase being largely attributed to higher instances of marijuana use [14]. The annual prevalence of marijuana use among college students in 2013 was 36 percent [10]. Initiation of cannabis use in college freshman is associated with several other factors, including disposable income, other illicit substance use, and tobacco and alcohol use [13]. Cannabis is used primarily to support social functioning and interactions among college [15].

Young adults have the highest rates of use of prescription opioid pain relievers, stimulants for the treatment of ADHD, and anti-anxiety drugs [48]. While heroin use among Americans aged 18-25 years increased 109\% from 2002-2004 and 20112013 and increased 58\% among Americans 26 years and older, the greater epidemic is dependence on prescription painkillers in the U.S [49]. People are 40 times more likely to be addicted to heroin if they are addicted to prescription (opioid) painkillers [49]. Nine in 10 people who use heroin use it with at least one other drug, and most use at least three other drugs SAMHSA [49] Opiate abuse is associated with a greater risk of HIV, hepatitis, and premature death. Hepatitis $\mathrm{C}$ incidence rates remain high, especially for young adults who are injection drug users [16]. Although declines were evident among reported cases overall during 2002-2009, an increase was observed among cases in the 15-24 year age group, representing an epidemic related to intravenous drug use among young adults [17].

In addition to substance use, co-occurring mental health disorders are an added challenge for young adults. Individuals with SUDs experience mental health disorders at higher rates than those without SUDs [18]. Young adulthood is a period of particular risk for mental health disorders. Of individuals who will experience a mental health disorder during their lifetime, $75 \%$ will be diagnosed by age 24 [19]. Nearly half of emerging adults are estimated to have had a mental health disorder in the prior year [20] and they have triple the suicide rate of their adolescent (12-17 year old) counterparts [19].

Young adults are more likely to stop substance abuse behaviors or to enter treatment as a result of negative consequences [21,22]. They are also less likely to be selfmotivated to enter treatment for substance abuse problems [23]. Smith \& colleagues [22] found that young adults are more likely to stop substance abuse behaviors as a result of external factors rather than as a result of damaged or diminished interpersonal relationships [22]. College students, in particular, are less likely to recognize the need for treatment or to seek help [24].

Young adult peer groups and social networks can have a strong impact on behavior. However, it is more common for young adults to be influenced to drink more than to be influenced to drink less [25]. In contrast, studies suggest that positive peer support is a key factor in maintaining sobriety [24]. Recent evidence suggests that the link between peer group and individual substance use patterns extends to online relationships [26].

Characteristically different from older adults at treatment intake. [27], young adults may require different programming components and interventions than their older counterparts $[1,28]$. For example, as age increases, higher levels of internal motivation, greater lengths of stay and higher rates of posttreatment abstinence are reported [29]. Younger adults and college students also respond differently to substance use treatment programming when compared to older adults [29]. As increasing numbers of young adults are able to access behavioral health services through expanded healthcare coverage, understanding the ways this subgroup differs from other segments of the general population will become increasingly important. One measure of treatment success is treatment retention. Treatment retention is a widely used proxy for 
treatment outcomes such as substance use relapse, recidivism to crime, and sustained recovery. Factors related to both treatment program characteristics and individual patient characteristics have been investigated for their impact on retention in treatment [30].

Longer periods of treatment engagement are also associated with lower readmission rates, [31] and longer length of stay in treatment is associated with better treatment outcomes including lower post-treatment substance use rates [30,32]. Although the significance of remaining in treatment is well established, leaving treatment prior to completion or against clinical advice remains a treatment concern [33] and is associated with less desirable treatment outcomes [34].

Most personal and substance use characteristics have been found to be inconsistent predictors of treatment retention and outcomes [35-38]. Age is the only socio-demographic characteristic that consistently predicts retention in substance abuse treatment regardless of gender, with older age associated with longer lengths of stay [39-41].

In summary, although the literature commonly describes risky behaviors during adolescence, several of the risk behaviors peak in the ages 18-25. The developmental dynamics of emerging adulthood are also associated with risk behaviors [6] that appear to rapidly decline following marriage and again after the birth of children typically in late twenties or early thirties [6]. Little research has investigated the characteristics and treatment behaviors, such as treatment retention, in young adults who attend private, residential substance abuse and mental health treatment. To address this research gap, the purpose of this study was to explore treatment retention in a sample of adults who enrolled in residential treatment for cooccurring substance use and mental health disorders. The study was designed to examine the effect of age on treatment retention in private residential dual diagnosis treatment. To that end, we were guided by two research questions:

a. Is there a difference in treatment retention between young adults and older adults? And

b. What factors influence treatment retention in each age group?

\section{Methods}

All participants received evidence-based individual and group interventions at one of three residential facilities operated by Foundations Recovery Network, a private for-profit provider of integrated treatment for mental health and substance use disorders. Though the treatment centers are located in Tennessee and California, participants were drawn from across the United States and Canada. Participants received an intake assessment by a multidisciplinary team, which provided the basis for an individual treatment plan to address substance use, psychiatric disorder, and medical and social service needs. Co-occurring disorders were assessed and monitored over the course of treatment starting with initial screening, assessment, and psychiatric evaluation. Each participant was assigned to one of the program's clinicians who utilize the information gathered through initial screening and assessment to develop an initial treatment plan with the patient during an initial individual session during the first week of treatment.

Ongoing psychiatric and individual therapy sessions were provided in conjunction with weekly treatment team meetings to update each patient's treatment plan. This process provided input from a multidisciplinary team in order to thoroughly assess co-occurring disorders throughout treatment as symptoms may change or become clearer during the course of treatment. The typically expected length of stay was between 28 and 40 days, however, recommended treatment duration was individualized based on clinical assessment and medical necessity. A total of 959 patients who entered treatment between February 1, 2008 and July 31, 2010 agreed to participate in the study. A trained intake staff member described the evaluation design, obtained informed consent, and collected baseline data. Follow-up data was collected at one-, six-, and twelve-months post discharge. A community-based Institutional Review Board reviewed and approved the study protocol to assure the protection of human subjects.

\section{Measurement}

\section{Addiction Severity}

The scalable questions that make up the composite indices of the Addiction Severity Index (ASI) [42] were utilized to measure addiction severity. The ASI was developed to measure problem severity in each of seven potential problem areas that include: medical, employment, alcohol, drug, legal, family/ social and psychiatric problems. In order to ensure that each question within a given problem area is given the same weight in calculation of the composite score each item in a subscale is divided by its maximum value and by the total number of questions in a composite. This scoring yields a score from 0-1 for each composite index.

\section{Readiness for Change}

The University of Rhode Island Change Assessment (URICA) [43] is a measure of readiness to change that has been studied with a range of different populations. The instrument consists of 32 statements that subjects endorse on a 5-point scale from strongly agree to strongly disagree. The URICA yields scores on each of four scales corresponding to the stages of change described by DiClemente \& Norcross [44] periodcontemplation, Contemplation, Action, and Maintenance. The scores from these sub-scales are used to create a Readiness to Change composite score by adding the Contemplation, Action, and Maintenance scores and subtracting the Pre-Contemplation score. The Readiness to Change score was derived for this study in the same manner used in Project MATCH [45]. The average Contemplation, Action, and Maintenance scores were added 


\section{Global Journal of Addiction \& Rehabilitation Medicine}

and the Pre-contemplation score was subtracted from the sum. Treatment Retention. Treatment retention was operationalized as length of stay, calculated as the total number of days between program start date and discharge date.

\section{Data Analysis}

Initial analyses consisted of basic descriptive statistics and bivariate analyses to identify and examine group differences on pre-treatment demographic and use-related variables as well as components of treatment retention. A life table was then developed to investigate the trajectory of treatment retention by age group and finally, Cox regression was employed to investigate the impact of various predictors of treatment retention by age group. The Cox regression allowed for the unbiased analysis of time to event data controlling for covariates. The event of interest in the current study is a discharge from treatment. Like logistic regression, the exponential of the coefficients from $97 \%$ of the young adults and $87.4 \%$ of the older adults. the Cox model provides the relative risk of the odds for the covariate but Cox regression also proves superior to ordinary least squares regression (OLS) by allowing for censoring of persons who discontinued or did not experience the event (treatment retention in the current study) during the study period.

\section{Results}

\section{Descriptive Analysis}

The results of descriptive analyses are presented in Table 1. The mean age of the total sample $(n=959)$ was slightly older than 37 years, with patients ranging from 18 to 74 years of age. Approximately $20 \%$ of the sample $(n=198)$ was between the ages of 18 and 25 . Overall, $41.5 \%$ of the participants were female with $37.4 \%$ of the young adults and $42.6 \%$ of older adults being female. The sample was primarily Caucasian: $89.4 \%$ overall and

Table 1: Sample Description.

\begin{tabular}{|c|c|c|c|c|}
\hline & $\begin{array}{c}\text { Young Adults } \\
\text { (18-25) } \\
\mathrm{N}=198(59.1 \%)\end{array}$ & $\begin{array}{c}\text { Older Adults } \\
\text { (26 \& older) } \\
\text { N=761 (40.9\%) }\end{array}$ & P Value & $\begin{array}{c}\text { Total Sample } \\
\text { N=959 }\end{array}$ \\
\hline & Mean (SD) & Mean (SD) & $\mathrm{p}$ value & Mean (SD) \\
\hline Age & 20.79 (1.93) & $41.24(9.78)$ & $<.001$ & $37.02(12.05)$ \\
\hline ASI: Medical & $.20(.31)$ & $.29(.38)$ & $<.01$ & $.27(.36)$ \\
\hline ASI: Employment/Support & $.47(.26)$ & $.39(.27)$ & $<.001$ & $.41(.27)$ \\
\hline ASI: Alcohol & $.22(.27)$ & $.42(.34)$ & $<.001$ & $.38(.34)$ \\
\hline ASI: Drug & $.24(.15)$ & $.15(.15)$ & $<.001$ & $.17(.16)$ \\
\hline ASI: Legal & $.21(.26)$ & $.09(.19)$ & $<.001$ & $.12(.21)$ \\
\hline $\begin{array}{l}\text { ASI: Family/Social } \\
\text { Relationships }\end{array}$ & $.32(.25)$ & $.30(.27)$ & n.s. & $.30(.26)$ \\
\hline ASI: Psychiatric & $.51(.19)$ & $.49(.21)$ & n.s. & $.49(.21)$ \\
\hline Readiness for Change & $10.62(1.46)$ & $10.82(1.59)$ & n.s, & $10.77(1.56)$ \\
\hline Precontemplation & $1.70(.54)$ & $1.66(.51)$ & n.s. & $1.67(.52)$ \\
\hline Contemplation & $4.39(.43)$ & $4.42(.44)$ & n.s. & $4.41(.44)$ \\
\hline Action & $4.23(.49)$ & $4.29(.47)$ & n.s. & $4.28(.47)$ \\
\hline Maintenance & $3.70(.57)$ & $3.77(.65)$ & n.s. & $3.76(.63)$ \\
\hline \multirow[t]{2}{*}{ Days in Treatment* } & $35.33(23.37)$ & $31.60(20.14)$ & $<.05$ & 32.38 (20.89) \\
\hline & $\mathrm{N}(\%)$ & $\mathrm{N}(\%)$ & & $\mathrm{N}(\%)$ \\
\hline $\begin{array}{c}\text { Treatment Retention at } 30 \\
\text { days-Yes }\end{array}$ & $98(49.5)$ & $301(39.6)$ & $<.05$ & $399(41.6)$ \\
\hline Gender Female & $74(37.4)$ & $324(42.6)$ & n.s. & $398(41.5)$ \\
\hline \multicolumn{5}{|c|}{ Race/Ethnicity } \\
\hline African American & $4(2.0)$ & $82(10.8)$ & $<.001$ & $86(9.0)$ \\
\hline Caucasian & $192(97.0)$ & 665 (87.4) & $<.001$ & 857 (89.4) \\
\hline Latino & $2(1.0)$ & $14(1.8)$ & n.s. & $16(1.7)$ \\
\hline $\begin{array}{l}\text { Employment in last } 30 \\
\text { days-Yes }\end{array}$ & $82(41.4)$ & 451 (59.3) & $<.001$ & $533(55.6)$ \\
\hline
\end{tabular}


Global Journal of Addiction \& Rehabilitation Medicine

\begin{tabular}{|c|c|c|c|c|}
\hline Alcohol & $131(66.2)$ & $567(74.5)$ & $<.05$ & $698(72.8)$ \\
\hline Cocaine & $56(28.3)$ & $186(24.4)$ & n.s. & $242(25.2)$ \\
\hline Cannabis & $123(62.1)$ & $177(23.0)$ & $<.001$ & $300(31.3)$ \\
\hline Opioid & $113(57.1)$ & $240(31.5)$ & $<.001$ & $353(36.8)$ \\
\hline Multiple Drug & $138(69.7)$ & $367(48.2)$ & $<.001$ & $505(52.7)$ \\
\hline Others & $2(1.0)$ & $14(1.8)$ & n.s. & $16(1.7)$ \\
\hline Major Depression & $147(74.2)$ & $589(77.4)$ & n.s & $736(76.7)$ \\
\hline Anxiety Disorder & $175(87.9)$ & $634(83.3)$ & n.s & $808(84.3)$ \\
\hline Mood Disorder & $58(29.3)$ & $279(36.7)$ & n.s. & $337(35.1)$ \\
\hline Bi-Polar Disorder & $3(1.5)$ & $8(1.1)$ & n.s. & $11(1.1)$ \\
\hline Eating Disorder & $2(1.0)$ & $6(0.8)$ & n.s. & $8(0.8)$ \\
\hline ADHD & $3(1.5)$ & $7(5.9)$ & n.s. & $10(1.0)$ \\
\hline Dementia & $5(2.5)$ & $37(4.9)$ & n.s. & $17(1.8)$ \\
\hline Missing & $8(4.0)$ & & & $45(4.7)$ \\
\hline
\end{tabular}

Statistically significant differences were found between young and older adults on five of the seven ASI composite indices. Younger adults entered treatment with greater severity on the drug, legal, and employment subscales and lesser severity on the medical and alcohol subscales. Younger adults were less likely to be employed in the 30 days prior to intake and were also less likely to have used alcohol within the 30 days prior to treatment. Younger adults were more likely to report using cannabis, opioids, or multiple drugs in the 30 days prior to admission. There were no significant differences in readiness to change scores, ASI composite indices for relationships and psychological issues or gender between the two groups at intake. There were also no statistically significant differences in days of use prior to treatment between younger and older adults for cocaine, sedatives or hallucinogens. Additionally, there were no statistically significant differences on mental health diagnoses between younger and older adults at admission (Table 1).

Results of the young adults Cox regression model indicate that three variables were associated with the likelihood of remaining in treatment. The probability of remaining in treatment was reduced by $32.4 \%$ for young adult females when compared to their male counterparts $(\mathrm{p}=.03)$. The probability of young adults remaining in treatment was also significantly associated with their ASI employment subscale score. Higher severity of substance use-related employment problems resulted

Table 2: Cox Regression Models for Treatment Retention. in a lower likelihood of remaining in treatment $(p=.018)$. A oneunit increase in employment severity reduced the likelihood of remaining in treatment by $59.8 \%$. In addition, young adults who scored higher on the contemplation subscale of the URICA at treatment entry were less likely to remain in treatment $(p=.021)$. In this case, being a young adult and entering treatment in the contemplative stage of change reduced the probability of remaining in treatment by $50.5 \%$.

Older adult retention was predicted by four factors. Similar to younger adults, female adults over the age of 25 were less likely to remain in treatment than their male counterparts $(\mathrm{p}=.007)$. The probability of remaining in treatment for female patients over 25 years of age was reduced by $23.2 \%$ as compared to males in the same age group. When compared to a mood disorder, patients over the age of 25 who had a diagnosis of dementia were two times more likely to remain in treatment $(\mathrm{p}=.033)$. Also similar to younger adults, greater severity on the ASI subscale score for employment reduced the probability of remaining in treatment for adults over 25 years of age by $37 \%$ for every one-unit increase in severity. Finally, adults over the age of 25 were less likely to remain in treatment as their ASI psychiatric composite scores increased ( $p=.004)$. The likelihood of remaining in treatment was reduced by $61.6 \%$ for each unit increase in severity of the psychiatric subscale score (Table 2).

\begin{tabular}{|c|c|c|c|c|c|c|c|c|c|c|}
\hline \multirow[b]{2}{*}{ Variables } & \multicolumn{5}{|c|}{ Model for Young Adults } & \multicolumn{4}{|c|}{ Model for Adults } & \multirow[b]{2}{*}{$95 \% \mathrm{CI}$} \\
\hline & B & SE & $\operatorname{Exp}(B)$ & P-Value & $95 \% \mathrm{CI}$ & $\mathrm{B}$ & SE & $\operatorname{Exp}(B)$ & P-Value & \\
\hline Female & -.392 & .181 & .676 & .030 & $\begin{array}{l}(.474- \\
.963) \\
\end{array}$ & -.264 & .098 & .768 & .007 & $\begin{array}{l}(.634- \\
.929)\end{array}$ \\
\hline Caucasian $^{1}$ & -.089 & .450 & .915 & .843 & $\begin{array}{l}(.379- \\
2.209)\end{array}$ & -.224 & .136 & .799 & .099 & $\begin{array}{l}(.613- \\
1.043)\end{array}$ \\
\hline $\begin{array}{l}\text { Employed in last } \\
\text { 30days--yes }\end{array}$ & -.334 & .208 & .716 & .108 & $\begin{array}{l}(.476- \\
1.076)\end{array}$ & -.095 & .118 & .909 & .419 & $\begin{array}{l}(.722- \\
1.145)\end{array}$ \\
\hline $\begin{array}{l}\text { Opiate Abuse/ } \\
\text { Dependence }\end{array}$ & .361 & .249 & 1.435 & .147 & $\begin{array}{l}(.881- \\
2.339)\end{array}$ & .237 & .146 & 1.268 & .103 & $\begin{array}{l}(.953- \\
1.687)\end{array}$ \\
\hline
\end{tabular}




\section{Global Journal of Addiction \& Rehabilitation Medicine}

\begin{tabular}{|c|c|c|c|c|c|c|c|c|c|c|}
\hline $\begin{array}{l}\text { Cocaine Abuse/ } \\
\text { Dependence }^{2}\end{array}$ & -.129 & .303 & .879 & .670 & $\begin{array}{l}(.486- \\
1.591)\end{array}$ & -.261 & .143 & .770 & .067 & $\begin{array}{l}(.582- \\
1.019)\end{array}$ \\
\hline $\begin{array}{l}\text { Cannabis Abuse/ } \\
\text { Dependence }^{2}\end{array}$ & .223 & .273 & 1.249 & .415 & $\begin{array}{l}(.732- \\
2.133)\end{array}$ & -.203 & .229 & .816 & .375 & $\begin{array}{l}(.521- \\
1.278)\end{array}$ \\
\hline $\begin{array}{c}\text { Poly Substance Abuse/ } \\
\text { Dependence }{ }^{2}\end{array}$ & .006 & .253 & 1.006 & .982 & $\begin{array}{l}(.613- \\
1.651)\end{array}$ & .082 & .168 & 1.086 & .623 & $\begin{array}{l}(.782- \\
1.508)\end{array}$ \\
\hline Depression & .128 & .244 & 1.136 & .601 & $\begin{array}{l}(.704- \\
1.834)\end{array}$ & .267 & .146 & 1.307 & .066 & $\begin{array}{l}(.982- \\
1.738)\end{array}$ \\
\hline Anxiety Disorder ${ }^{3}$ & -.071 & .308 & .931 & .816 & $\begin{array}{l}(.510- \\
1.701)\end{array}$ & -.029 & .158 & .972 & .855 & $\begin{array}{l}(.713- \\
1.324)\end{array}$ \\
\hline Bipolar $^{3}$ & .306 & .791 & 1.358 & .698 & $\begin{array}{l}(.288- \\
6.396)\end{array}$ & -.752 & .831 & .472 & .366 & $\begin{array}{l}(.092- \\
2.406)\end{array}$ \\
\hline Eating Disorder ${ }^{3}$ & -.245 & .806 & .783 & .761 & $\begin{array}{l}(.161- \\
3.801)\end{array}$ & -.607 & .521 & .545 & .243 & $\begin{array}{l}(.196- \\
1.512)\end{array}$ \\
\hline $\mathrm{ADHD}^{3}$ & 1.085 & .642 & 2.958 & .091 & $\begin{array}{l}(.840- \\
10.420)\end{array}$ & -.218 & .523 & .804 & .676 & $\begin{array}{l}(.289- \\
2.239)\end{array}$ \\
\hline Dimentia $^{3}$ & .053 & .505 & 1.054 & .917 & $\begin{array}{l}(.392- \\
2.835)\end{array}$ & .743 & .349 & 2.103 & .033 & $\begin{array}{l}(1.061- \\
4.169)\end{array}$ \\
\hline $\begin{array}{l}\text { Missing Mental } \\
\text { Disorders--Yes }\end{array}$ & -.031 & .468 & .969 & .947 & $\begin{array}{l}(.388- \\
2.423)\end{array}$ & .410 & .265 & 1.506 & .122 & $\begin{array}{l}(.896- \\
2.532)\end{array}$ \\
\hline ASI: Medical & -.102 & .267 & .903 & .703 & $\begin{array}{l}(.535- \\
1.525)\end{array}$ & -.131 & .126 & .877 & .298 & $\begin{array}{l}(.685- \\
1.123)\end{array}$ \\
\hline ASI: Employment & -.911 & .385 & .402 & .018 & $\begin{array}{l}(.189- \\
.855)\end{array}$ & -.461 & .210 & .630 & .028 & $\begin{array}{l}(.418- \\
.951)\end{array}$ \\
\hline ASI: Alcohol & .564 & .343 & 1.758 & .100 & $\begin{array}{l}(.897- \\
3.445)\end{array}$ & .034 & .155 & 1.034 & .829 & $\begin{array}{l}(.762- \\
1.403)\end{array}$ \\
\hline ASI: Drug & .638 & .652 & 1.894 & .327 & $\begin{array}{l}(.528- \\
6.792)\end{array}$ & .133 & .376 & 1.142 & .724 & $\begin{array}{l}(.547- \\
2.386)\end{array}$ \\
\hline ASI: Legal & .273 & .317 & 1.314 & .389 & $\begin{array}{l}(.706- \\
2.448)\end{array}$ & -.481 & .260 & .618 & .065 & $\begin{array}{l}(.371- \\
1.030)\end{array}$ \\
\hline ASI: Family/Support & -.008 & .348 & .992 & .982 & $\begin{array}{l}(.502- \\
1.962)\end{array}$ & -.229 & .181 & .795 & .207 & $\begin{array}{l}(.557- \\
1.135)\end{array}$ \\
\hline ASI: Psychiatric & -.915 & .618 & .401 & .139 & $\begin{array}{l}(.119- \\
1.347)\end{array}$ & -.957 & .330 & .384 & .004 & $\begin{array}{l}(.201- \\
.733)\end{array}$ \\
\hline \multicolumn{11}{|c|}{ Readiness to Change } \\
\hline Precontemplation & -.124 & .211 & .883 & .557 & $\begin{array}{l}(.584- \\
1.336)\end{array}$ & -.069 & .118 & .933 & .557 & $\begin{array}{l}(.740- \\
1.176)\end{array}$ \\
\hline Contemplation & -.704 & .306 & .495 & .021 & $\begin{array}{l}(.272- \\
.901)\end{array}$ & -.075 & .169 & .928 & .658 & $\begin{array}{l}(.666- \\
1.293)\end{array}$ \\
\hline Action & -.035 & .229 & .965 & .878 & $\begin{array}{l}(.617- \\
1.512)\end{array}$ & .120 & .132 & 1.128 & .360 & $\begin{array}{l}(.872- \\
1.460)\end{array}$ \\
\hline Maintenance & -.134 & .164 & .874 & .413 & $\begin{array}{l}(.634- \\
1.206)\end{array}$ & -.054 & .077 & .948 & .486 & $\begin{array}{l}(.815- \\
1.102)\end{array}$ \\
\hline -2 Log Likelihood & \multicolumn{5}{|c|}{1547.639} & \multicolumn{5}{|c|}{5780.432} \\
\hline$\chi^{2}, \mathrm{df}, \mathrm{p}$-value & \multicolumn{5}{|c|}{$40.405,25, .026^{*}$} & \multicolumn{5}{|c|}{$84.999,25, .000^{* * *}$} \\
\hline
\end{tabular}

${ }^{1}$ African American and Latino were the reference group.

${ }^{2} \mathrm{Alcohol}$ abuse/dependences and others were the reference group

${ }^{3}$ Mood disorders was the reference group 
The survival lines, indicating time to discharge for both young and older adults, are illustrated in Figure 1. Survival lines remain similar for the first 20 days of treatment. However, after 25 days the lines split into different trajectories that continue to broaden as time progresses. At 30 days, approximately $50 \%$ of young adults remained in treatment compared to less than $40 \%$ of older adults. Comparison of the survival lines was performed using the Wilcoxon (Gehan) statistic (5.196, df= 1,p< .05). This result further highlights the statistical significance of the differences in the trajectories of these lines (Figure 1).

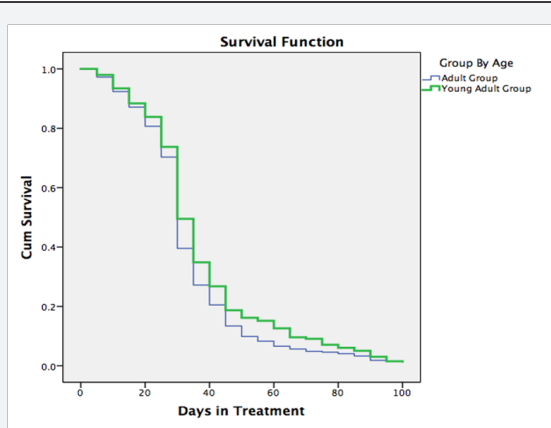

Figure 1: Life Table-Days in Treatment by Age Group.

\section{Discussion}

Historically, age has been a consistent predictor of treatment retention. Unlike many prior studies that found older age predicted longer length of stay in treatment, this study found that the young adult age group (18-25) remained in treatment longer than the group of adults age 26 and older. During the first 25 days there was little difference in retention between the two groups, but at 30 days only $40 \%$ of adults over age 26 remained in treatment while $50 \%$ of the younger adults remained in treatment. This separation in retention between the two age groups was sustained over the next 60 through 90 days when the retention within both groups became essentially the same. A higher rate of employment in older adults at treatment admission is one possible explanation for the disparity in retention observed between the two groups. Older adulthood is more likely to include greater social and familial responsibilities, which might require these patients to return home earlier than their younger counterparts.

Young adults presented to treatment with greater severity of legal issues, which may motivate them to remain in treatment longer. This finding would be consistent with findings that young adults are more likely to be externally motivated to address substance use problems [22,23,46]. Although there were not significant differences in the severity of the family and social relationships, it is possible that external support or pressure could also influence young adults' decisions to remain in treatment longer. Similarly, young adults may be more influenced by peer groups [24] such as those found in therapeutic communities, which could also have contributed to the differences seen in retention. In a Canadian study examining motivation to treatment among young adults ages 16-24 entering outpatient substance use treatment, [23] found that peer pressure to reduce alcohol or substance use was positively correlated with supportive treatment motivation and was not perceived as coercion.

This was in contrast to parental pressure to reduce alcohol or substance use which was perceived as external coercion [23]. Similar perceptions of peer pressure to enter treatment as supportive and parental pressure to enter treatment as coercive hold opportunities for engaging peer support and peer messaging to motivate retention in treatment Goodman et al. [23]. Peer support promotes self-efficacy and also provides an opportunity for individuals to actively engage in treatment through leadership and modeling within the group treatment setting [50]. Finally, it is possible that programming was a determining factor in the decision to remain in treatment. Relevant and timely treatment programming that sufficiently engaged the younger adult group to remain in treatment may have tipped the balance in young adults, especially in combination with other factors listed above.

The older age group had greater severity of alcohol and medical problems and nearly $60 \%$ had been employed in the 30 days prior to admission. This is not surprising given the emergence of physical health problems associated with aging such as hypertension, cardiovascular disease, stroke, cancer, diabetes, obesity, arthritis, excess alcohol use, tobacco use, depression and dementia which are exacerbated by heavy alcohol use [47]. This finding is congruent with national findings that current, binge, and heavy alcohol use are highest among the age group 21-25 year olds, current, binge, and heavy alcohol use remains high with only a gradual decrease over time across the remaining adult age groups.While the short-term risks of excess alcohol use and binge drinking include injuries such as motor vehicle crashes, violence such as sexual assault, intimate partner violence or suicide, alcohol poisoning, risky sexual behaviors and adverse birth outcomes, the cumulative health effects of over time are associated with chronic diseases identified above [47].

The young adult group had greater severity of drug, legal, and employment/support problems and a pattern of cannabis, opioid, and multiple drug use compared to the older adults. This is also not a surprising finding given national survey findings that young adults age 18 to 25 have the highest use of all categories of illicit drugs (21.5\%) and marijuana (19.1\%) compared to adults 26 and older use of illicit drugs (7.3\%) and marijuana (5.6\%). While the number of new nonmedical users of pain relievers in 2013 (1.5 million) was lower than the numbers in 2002 through 2012 (ranging from 1.9 million to 2.5 million), it is important to note that the average ages at first nonmedical use was 21.7 years for pain relievers. Other first nonmedical uses of psychotherapeutics in 2013 were 21.6 years for stimulants, 25.0 years for sedatives, and 25.4 years for tranquilizers [48-50]. 


\section{Global Journal of Addiction \& Rehabilitation Medicine}

With the legalization of medical marijuana and recreational marijuana in a small but increasing number of state laws, over $53 \%$ of Americans favored legalization of marijuana Pew Report [51], and adolescents aged 12 to 17 have a decreasing perceived risk of marijuana use indicating smoking marijuana once or twice a week from $54.6 \%$ in 2007 to $39.5 \%$ in 2013. Decrease in perceived risk is commonly associated with increased use of substances, further contributing to the mix of polysubstance use. The two age groups differed in the predictors of treatment retention. Young adults were more likely to leave treatment prematurely if they were female, had greater employment severity, and scored highest on the Contemplative Stage in the Readiness to Change Assessment.

The older adults were more likely to leave if they were female, had a mental health diagnosis of dementia, and had greater severity on employment composite subscale and the psychiatric composite subscale of the ASI. Women in both the young adult and older adult groups were more likely to leave treatment prematurely than men in both age groups. Gender as a predictor of treatment retention has mixed findings with studies reporting shorter treatment retention for women primarily reported in programs specifically designed for women-only within the context of trauma-informed care [52]. A genderspecific group treatment focused on women's substance abuse treatment needs may enhance longer-term clinical outcomes for women with substance use disorders [8].

Collectively, these findings suggest that young adults age 1825 with risky alcohol and substance use pose both challenges and opportunities to engage and retain in effective treatment programs. While legal problems coupled with parental or employer pressure may provide extrinsic motivation causing a young adult to enter substance use treatment, they are more likely to actively engage in treatment if peer support and relevant and timely programming foster intrinsic self-motivation. Recent systematic reviews of psychosocial interventions for substance use disorders for young adults indicate that brief interventions resulted in decreased alcohol intake and alcohol related problems with greater effect size reflected in interventions that included motivational interviewing, decisional balance, and goal-setting exercises [53,54].

Similarly, a systematic review of computer-based interventions identified less substance use, greater motivation to change, improved treatment retention, and increased knowledge about substance use information when compared to treatment as usual [55]. Programs serving younger adults should focus on behaviors associated with multiple substances of abuse as well as illicit drug use [56]. These programs should also consider providing services to address pending legal issues and perhaps extending the length of engagement in therapeutic services to support the timely and successful closure of legal issues. Central to the transition from illicit drug culture for many young adults will be services that support both life skill development and emotional resilience $[57,58]$.
The findings of this study must be considered in light of its limitations. The study was based on data from private sector substance abuse treatment programs with nearly $90 \%$ of sample being Caucasian. Although this limits generalizability to other ethnic and minority groups, it is one of the few studies of private sector patients with a large sample size. The study population used here is both a limitation and strength. While it may be limited in generalizability across a broad spectrum of programs, it is one of few studies examining treatment retention in private residential treatment. In conclusion, data collected in this study suggest that there are some important differences in presentation at treatment between adults aged 18-25 and older adults and that these differences may predict length of stay in treatment. By exploring these differences, program administrators can better tailor services to support retention in treatment and improve treatment outcomes.

\section{References}

1. Arnett JJ (2000) Emerging adulthood: A theory of development from the late teens through the twenties. Am Psychol 55(5): 469-480.

2. Davis C, Kelly J (2012) Risk-taking, harm and help-seeking reported by young people in treatment at a youth alcohol and drug counselling service. Youth Studies Australia 31(4): 35-45.

3. Office of the Press Secretary (2014) FACT SHEET: Affordable Care Act by the Numbers. The White House, USA.

4. Staley MJ, Carson JA (2014) Health Insurance Among Young Adults Rebounds Post Recession". Carsey Research. Carsey School of Public Policy, USA, National Issue Brief 77.

5. Kessler RC, Berglund P, Demler O, Jin R, Merikangas KR, et al. (2005) Lifetime prevalence and age-of-onset distributions of DSMIV disorders in the National Comorbidity Survey Replication. Archives of General Psychiatry 62(6): 593-602.

6. Bachman JG, Johnston LD, O Malley PM, Schulenberg P (1996) Transitions in drug use during late adolescence and young adulthood. In JA Graber, J. Brooks-Gunn \& AC Petersen Transitions through adolescence: Interpersonal domains and context, Mahwah, N] Lawrence Erlbaum, pp. 111-140.

7. Rooney M, Chronis Tuscano A, Yoon Y (2012) Substance Use in College Students with ADHD. Journal of Attention Disorders 16: 221-234.

8. Greenfield BL, Venner KL, Kelly JF, Slaymaker V, Bryan AD (2012) The impact of depression on abstinence self-efficacy and substance use outcomes among emerging adults in residential treatment. Psychology of Addictive Behaviors 26(2): 246-254.

9. Mallett KA, Lee CM, Neighbors C, Larimer ME, Turrisi R (2006) Do we learn from our mistakes? An examination of the impact of negative alcohol-related consequences on college students drinking patterns and perceptions. Journal of Studies on Alcohol 67(2): 269-276.

10. Johnston LD, O Malley PM, Miech RA, Bachman JG, Schulenberg JE (2014) Monitoring the Future national results on drug use: 19752013: Overview, Key Findings on Adolescent Drug Use. Ann Arbor: Institute for Social Research, The University of Michigan, USA.

11. National Institute of Drug Abuse (2013) Sixty percent of 12th graders do not view regular marijuana use as harmful. Advancing Addiction Science, USA.

12. Gfroerer JC, Greenblatt JC, Wright DA (1997) Substance use in the U.S college-age population: Differences according to educational status and living arrangement. American Journal of Public Health 87(1): 6265. 


\section{Global Journal of Addiction \& Rehabilitation Medicine}

13. Suerken CK, Reboussin BA, Sutfin EL, Wagoner KG, Spangler J, et al. (2014) Prevalence of marijuana use at college entry and risk factors for initiation during freshman year. Addictive Behaviors 39(1): 302-307.

14. Johnston LD, OMalley PM, Bachman JG, Schulenberg JE (2013) Monitoring the Future national survey results on drug use, 19752012: Volume 2, College students and adults ages 19-50. Ann Arbor: Institute for Social Research, The University of Michigan, USA.

15. Beck KH, Caldeira KM, Vincent KB, O Grady KE, Wish ED, et al. (2009) The social context of cannabis use: Relationship to cannabis use disorder and depressive symptoms among college students. Addictive Behaviors 34(9): 764-768.

16. Page KM (2013) Injection drug use and Hepatitis C virus Infection in young adult injectors: Using evidence to inform comprehensive prevention. Clinical Infectious Disease 57(2): S32-38.

17. Centers for Disease Control (CDC) (2011) Hepatitis C Virus infection among adolescents and young adults Massachusetts, 2002-2009. Morbidity and Mortality Weekly Report, 60(17): 537-541.

18. Compton WM, Thomas YF, Stinson FS, Grant BF (2007) Prevalence, correlates, disability, and comorbidity of DSM-IV drug abuse and dependence in the United States: results from the national epidemiologic survey on alcohol and related conditions. Archives of General Psychiatry 64(5): 566-76.

19. Park MJ, Mulye TP, Adams SH, Brindis CD, Irwin CE (2006) The health status of young adults in the United States. Journal of Adolescent Health 39(3): 305-317.

20. Blanco C, Okuda M, Wright C, Hasin DS, Grant BF, et al. (2008) Mental health of college students and their non-college-attending peers: Results from the National Epidemiologic Study on Alcohol and Related Conditions. Archives of General Psychiatry 65(12): 1429-1437.

21. Morse S, MacMaster S (2015) Characteristics and outcomes of young adult opiate users receiving residential substance abuse treatment. Journal of Evidence Informed Social Work 12(16): 556-566.

22. Smith DC, Cleeland L, Dennis ML (2010) Reasons for quitting among emerging adults and adolescents in substance-use-disorder treatment. Journal of Studies on Alcohol and Drugs 71(3): 400-409.

23. Goodman I, Peterson Badali M, Henderson J (2011) Understanding motivation for substance use treatment: The role of social pressure during the transition to adulthood. Addictive Behaviors 36(6): 660668.

24. Caldeira KM, Kasperski SJ, Sharma E, Vincent KB, O Grady, et al. (2009) College students rarely seek help despite serious substance use problems. Journal of Substance Abuse Treatment 37(4): 368-378.

25. Astudillo M, Connor J, Roiblatt RW, Ibanger AKJ, Gmel G (2013) Influence from friends to drink more or drink less: A cross national comparison. Addictive Behaviors 38(11): 2675-2682.

26. Cook SH, Bauermeister JA, Gordon Messer D, Zimmerman M (2013) Online network influences on emerging adults' alcohol and drug use. Journal of Youth and Adolescence 42(11): 1674-1686.

27. Urbanski KA, Kelly JF, Hoeppner BB, Slaymaker V (2012) The role of therapeutic alliance in substance use disorder treatment for young adults. Journal of Substance Abuse Treatment 43(3): 344-351.

28. Smith DC, Godley SH, Godley MD, Dennis ML (2011) Adolescent community reinforcement approach outcomes differ among emerging adults and adolescents. Journal of Substance Abuse Treatment 41(4): 422-430.

29. Satre DD, Mertens J, Arean PA, Weisner C (2003) Contrasting outcomes of older versus middle-aged and younger adult chemical dependency patients in a managed care environment. Journal of Studies on Alcoho 64(4): 520-530.
30. Greenfield L, Burgdorf K, Chen X, Porowski A, Roberts T, Herrell $J$ (2003) Effectiveness of long-term residential substance abuse treatment for women: Findings from three national studies. American Journal of Drug and Alcohol Abuse 30(3): 537-550.

31. Moos RH, Moos BS (1995) Stay in residential facilities and mental health care as predictors of readmission for patients with substance use disorders. Psychiatric Services 46(1): 66-72.

32. Simpson DD, Joe GW, Rowan Szal RG (1997) Drug abuse treatment retention and process effects on follow-up outcomes. Drug and Alcohol Dependence 47(3): 227-235

33. Ball SA, Carroll KM, Canning Ball M, Rounsaville BJ (2006) Reasons for dropout from drug abuse treatment: Symptoms, personality, and motivation. Addictive Behaviors 31(2): 320-330.

34. Deane FP, Wootton DJ, Hsu C, Kelly PJ (2012) Predicting dropout in the first 3 months of 12-step residential drug and alcohol treatment in an Australian sample. Journal of Studies on Alcohol and Drugs 73(2): 216225.

35. Hiller ML, Knight K, Leukefeld C, Simpson DD (2002) Motivation as a predictor of therapeutic engagement in mandated residential substance abuse treatment. Criminal Justice and Behavior 29(1): 5675.

36. Hser YI, Joshi V, Maglione M, Chou CP, Anglin MD (2001) Effects of program and patient characteristics on retention of drug treatment patients. Evaluation Program Planning 24(4): 331-341.

37. Joe GW, Simpson DD, Broome KM (1998) Effects of readiness for drug abuse treatment on client retention and assessment of process. Addiction 93(8): 177-1190.

38. Joe GW, Simpson DD, Broome KM (1999) Retention and patient engagement models for different treatment modalities in DATOS. Drug and Alcohol Dependence 57(2): 113-125.

39. Adams SM, Peden AR, Hall LA, Rayens MK, Staten R, Leukefeld CG (2011) Predictors of retention of women offenders in a communitybased residential substance abuse treatment program. Journal of Addictions Nursing 23(3): 103-116.

40. Hall EA, Prendergast ML, Wellisch J, Patten M, Cao Y (2004) Treating drug-abusing women prisoners: An outcomes evaluation of the Forever Free program. The Prison Journal, 84(1): 81-105.

41. Pelissier B, Motivans M, Rounds Bryant JL (2005) Substance abuse treatment outcomes: A multi-site study of male and female prison programs. Journal of Offender Rehabilitation 41(2): 57-80.

42. McClellan AT, Kushner H, Metzger D, Peters R, Smith I, et al. (1992) The fifth edition of the Addiction Severity Index.Journal of Substance Abuse Treatment 9(3): 199-213.

43. DiClemente CC, Hughes SO (1990) Stages of change profiles in outpatient alcoholism treatment. Journal of Substance Abuse 2(2): 217-235.

44. Prochaska JO, DiClemente CC, Norcross JC (1992) In search of how people change: Applications to addictive behaviors. American Psychologist 47(9): 1102-1114.

45. Project MATCH Research Group (1997) Matching alcoholism treatment to client heterogeneity: Project MATCH post treatment drinking outcomes. Journal of Studies on Alcohol 58(1): 7-29.

46. Morse S, MacMaster S (2015) Characteristics and outcomes of young adult opiate users receiving residential substance abuse treatment. Journal of Evidence Informed Social Work 12(6): 556-66.

47. Centers for Disease Control (CDC) (2016) Fact sheets: Alcohol use and your health. CDC Government, USA. 
48. Substance Abuse and Mental Health Services Administration (2013) Results from the 2012 National Survey on Drug Use and Health: Summary of National Findings, NSDUH Series H-46, HHS Publication No. (SMA) 13-4795. Rockville, MD: Substance Abuse and Mental Health Services Administration, USA.

49. Substance Abuse and Mental Health Services Administration (2014) Results from the 2013 National Survey on Drug Use and Health: Summary of National Findings, NSDUH Series H-48, HHS Publication No. (SMA) 14-4863. Rockville, MD: Substance Abuse and Mental Health Services Administration, USA.

50. Substance Abuse and Mental Health Services Administration. (2015) Behavioral health trends in the United States: Results from the 2014 National Survey on Drug Use and Health, NSDUH Series H-50, HHS Publication No. (SMA) 15-4927). Rockville, MD: Substance Abuse and Mental Health Services Administration, USA.

51. Pew Report (2013) Majority now supports legalizing marijuana. Pew Research Center, USA.

52. Greenfield SF, Trucco EM, McHugh RK, Lincoln M, Gallop RJ (2007) The Women's Recovery Group Study: A Stage I trial of women-focused group therapy for substance use disorders versus mixed-gender group drug counseling. Drug and Alcohol Dependence 90(1): 39-47.
53. Klimas J, Tobin H, Field CA, O Gorman CS, Glynn LG, et al. (2014). Psychosocial interventions to reduce alcohol consumption in concurrent problem alcohol and illicit drug users. Cochrane Database of Systematic Reviews 3(12): CD009269.

54. Tanner Smith EE, Lipsey MW (2015) Brief alcohol interventions for adolescents and young adults: A systematic review and meta-analysis. Journal of Substance Abuse Treatment 51: 1-18.

55. Moore BA, Fazzino T, Garnet B, Cutter CJ, Barry DT (2011) Computerbased interventions for drug use disorders: A systematic review. Journal of Substance Abuse Treatment 40(3): 215-223.

56. Ihongbe TO, Masho SW (2016) Prevalence, correlates and patterns of heroin use among young adults in the United States. Addictive Behaviors 63: 74-81.

57. Kessler RC, Nelson CB, McGonagle KA, Edlund MJ, Frank RG, et al. (1996) The epidemiology of co-occurring addictive and mental disorders Implications for prevention and service utilization. American Journal of Orthopsychiatry 66(1): 17-31.

58. Kypri K, McCarthy DM, Coe MT, Brown SA (2004) Transition to independent living and substance involvement of treatment and high risk youth. Journal of Child and Adolescent Substance Abuse 13(3): 85100 .

\begin{tabular}{l} 
Your next submission with Juniper Publishers \\
will reach you the below assets \\
- Quality Editorial service \\
- Swift Peer Review \\
- Reprints availability \\
- E-prints Service \\
- Manuscript Podcast for convenient understanding \\
- Global attainment for your research \\
- Manuscript accessibility in different formats \\
( Pdf, E-pub, Full Text, Audio) \\
- Unceasing customer service \\
Track the below URL for one-step submission \\
https://juniperpublishers.com/online-submission.php \\
\hline
\end{tabular}

